\title{
Karakorum temperature out of phase with hemispheric trends for the past five centuries
}

\author{
Muhammad Usama Zafar ${ }^{1,7} \cdot$ Moinuddin Ahmed ${ }^{1} \cdot$ Mukund Palat Rao $^{2,3} \cdot$ \\ Brendan M. Buckley ${ }^{2}$ Nasrullah Khan ${ }^{4} \cdot$ Muhammad Wahab $^{5,8} \cdot$ Jonathan Palmer $^{6}$
}

Received: 17 September 2014 / Accepted: 22 May 2015

(C) Springer-Verlag Berlin Heidelberg 2015

\begin{abstract}
A systematic increase in global temperature since the industrial revolution has been attributed to anthropogenic forcing. This increase has been especially evident over the Himalayas and Central Asia and is touted as a major contributing factor for glacier mass balance declines across much of this region. However, glaciers of Pakistan's Karakorum region have shown no such decline during this time period, and in some instances have exhibited slight advance. This discrepancy, known as the 'Karakorum Anomaly', has been attributed to unusual amounts of debris covering the region's glaciers; the unique seasonality of the region's precipitation; and localized cooling resulting from increased cloudiness from monsoonal moisture. Here we present a tree-ring based reconstruction of summer (June-August) temperature from the Karakorum of North Pakistan that spans nearly five centuries (1523-2007 C.E.).
\end{abstract}

Electronic supplementary material The online version of this article (doi:10.1007/s00382-015-2685-z) contains supplementary material, which is available to authorized users.

Muhammad Usama Zafar

muhammadusamazafar@gmail.com

1 Laboratory of Dendrochronology and Plant Ecology, Department of Botany, Federal Urdu University of Arts, Science and Technology, Gulshan-e-Iqbal Campus, Karachi 75300, Pakistan

2 Tree Ring Laboratory, Lamont-Doherty Earth Observatory, Columbia University, Palisades, NY 10964, USA

3 Department of Earth and Environmental Science, Columbia University, New York, NY 10027, USA

4 Laboratory of Plant Ecology Department of Botany, University of Malakand, Khyber Pakhtunkhwa, Pakistan

5 Center for Plant Sciences and Biodiversity, University of Swat, Khyber Pakhtunkhwa, Pakistan
The ring width indices are derived from seven collections (six-Picea smithiana and one-Pinus gerardiana) from middle-to-upper timberline sites in the northern Karakorum valleys of Gilgit and Hunza at elevations ranging from 2850 to 3300 meters above mean sea level (mean elevation $3059 \mathrm{~m}$ asl). The reconstruction passes all traditional calibration-verification schemes and explains $41 \%$ of the variance of the nested Gilgit-Astore instrumental station data (Gilgit-1454 m asl, 1951-2009; Astore-2167 m asl, 1960-2013). Importantly, our results indicate that Karakorum temperature has remained decidedly out of phase with hemispheric temperature trends for at the least the past five centuries, highlighting the long-term stability of the Karakorum Anomaly, and suggesting that the region's temperature and cloudiness are contributing factors to the anomaly.

Keywords Karakorum Anomaly · Temperature · Dendroclimatology $\cdot$ High Asia $\cdot$ Glaciers

6 Climate Change Research Centre, School of Biological, Earth and Environmental Sciences, University of New South Wales, Sydney 2052, Australia

7 Present Address: Department of Environmental Science, Bahauddin Zakariya University, Multan 60000, Pakistan

8 Present Address: State Key Laboratory of Vegetation and Environmental Change, Institute of Botany, Chinese Academy of Sciences, Beijing 100093, China 

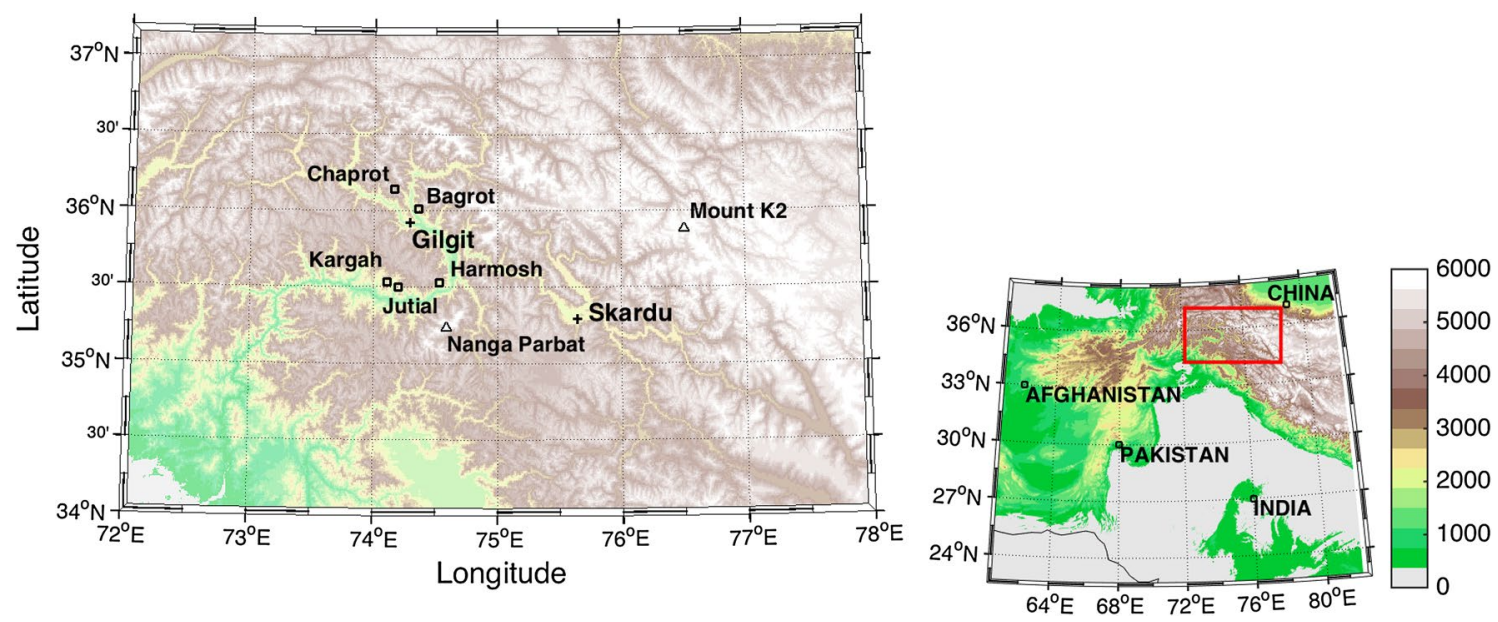

Fig. 1 Map showing the study sites outlined in Table 1 (Chaprot, Bagrot, Harmosh, Kargah, and Jutial) where samples were collected. The red box in the smaller inset highlights the area shown on the left. Mount K2 and Nanga Parbat are peaks above 8,000 m in elevation

\section{Introduction}

The Karakorum Mountain range of northern Pakistan is one of the most remote areas of the Himalayas, and maintains a place in history as home to several of the world's highest, most technically difficult, and most storied mountains for ascent. Adding to the Karakorum's mystique is that little research of any kind has been conducted in this region, particularly with regard to its paleoclimate. Dendroclimatology (tree-ring-based climate analysis) has been applied to analyze large-scale climate over High Asia (Cook et al. 2013a), and over several regions of the Himalaya, for example Cook et al. (2003), in Nepal; Dey and Kumar (1983), Douville and Royer (1996), Li and Yanai (1996), in the Indian Himalaya; Krusic et al. (2015), in Bhutan; and Ahmed et al. (2011), Cook et al. (2013b), Esper (2000), Esper et al. (2002), for parts of Pakistan. Here we present a calibrated and verified reconstruction of summer temperature (June-August) derived from seven tree ring records from the valleys of Gilgit and Hunza (Fig. 1), the first such calibrated and verified reconstruction from the Karakorum. Zafar et al. (2010), and Ahmed et al. (2013) first published these same tree ring records as an assessment of the dendroclimatic potential from the Karakorum, and Cook et al. (2013a), included them as part of a large ensemble (585 records) in a reconstruction of mid-to-high latitude Asian temperature over the past millennium. However, while the Cook et al. (2013a) reconstruction clearly shows the hemispheric scale warming over Asia, our regional record illustrates the out-of-phase nature of the Karakorum, as will be discussed later (Fig. 2).

Global temperature has steadily increased since the industrial revolution, markedly so over the Himalayas and Central Asia (Cook et al. 2013b; D'Arrigo et al. 2006; Davi et al. 2015; IPCC 2014; PAGES 2k Consortium 2013).
While this warming trend has contributed to glacier mass balance declines across most of 'High Asia', the glaciers of the Karakorum have either remained stable or advanced during this same time period, and this has become known as the 'Karakorum Anomaly' (Bolch et al. 2012; Gardelle et al. 2012; Hewitt 2005; Hewitt et al. 2011; Kapnick et al. 2014; Kumar et al. 2015; Minora et al. 2013).

Hewitt (2005) suggests that the apparently anomalous glacial stability of the Karakorum is in response to greater transport of summer monsoonal moisture that causes increased snowfall at high altitudes-a synoptic pattern that also results in increased cloudiness and summertime cooling in the region's valleys, such as Gilgit and Hunza in Pakistan's Karakorum. Two-thirds of high-altitude snow in the Karakorum accumulates in the winters and is caused by synoptic westerly disturbances, while the remainder accumulates during the summer months under the influence of the Indian Monsoon (Benn and Owen 1998; Bookhagen and Burbank 2010; Hewitt et al. 1988; Hewitt 2005; Palazzi et al. 2015). Similarly, Gardelle et al. (2012) and Farhan et al. (2015) also argue that the anomaly is a result of a combination of the region's unique precipitation and temperature dynamics. Both studies show that Karakorum summer mean temperature decreased between 1980 and 1995 (albeit increased since 1996, as also seen in our reconstruction, concurrent with an increase in winter precipitation). Alternative explanations have been offered by Minora et al. (2013) suggesting that high debris loading on regional glaciers serves to insulate them from the effects of warming, and Kapnick et al. (2014) who reason that the cause of the Karakorum Anomaly is the higher contribution of non-monsoonal wintertime snowfall compared to what is primarily monsoon-season snowfall in the Himalayas. The latter authors concluded that the unique precipitation 
Fig. 2 Three-panel plot showing z-scores of (top) Cook et al. (2013a) and Pages $2 \mathrm{k}$ Consortium (2013) High Asia summer (June-August-JJA) temperature reconstruction; (middle) Gilgit-Astore (JJA) temperature reconstruction from this study, (bottom) both reconstructions bandpassed to extract $20-40$ years periodicity and superimposed to illuminate the out of phase nature of the two reconstructions. Note the different $y$ axis scale for the bottom plot

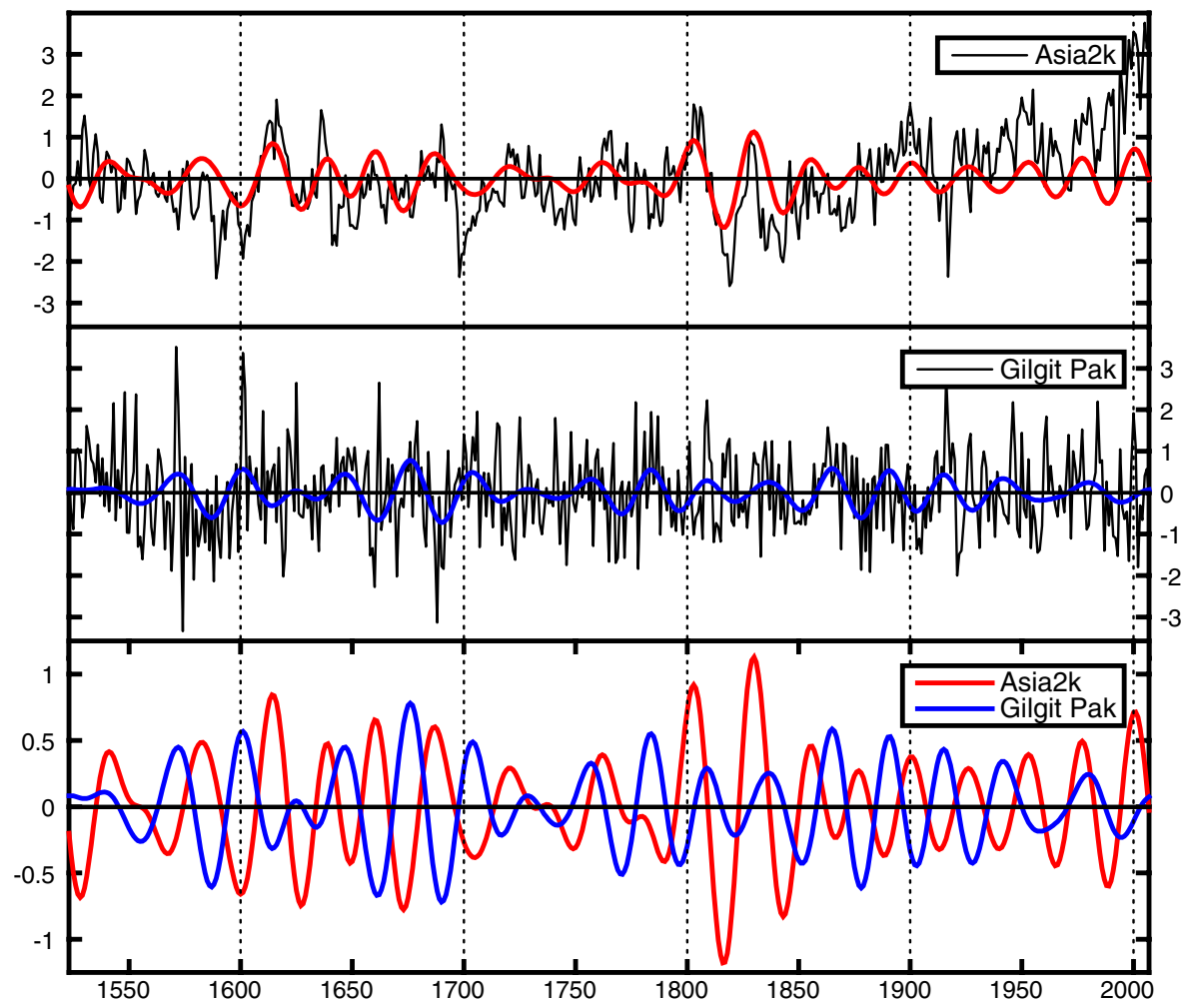

seasonality of the Karakorum serves to insulate the region from the broad scale glacial retreat that has been observed over the remainder of Himalayan and Central Asian glaciers.

In this paper we generate and analyze June through August (JJA) temperature trends for the Karakorum for the past five centuries based on crossdated tree-rings of spruce and pine. We conclude that the unique summer temperature dynamics of this region are strongly influenced by local cloudiness, and this is a contributing factor to the Karakorum Anomaly.

\section{Materials and methods}

\subsection{Tree ring data}

We used standard dendrochronological techniques and protocols for the collection, preparation, measuring and processing of samples obtained for this study (e.g. Cook and Kairiukstis 1990; Fritts 1976; Stokes and Smiley 1968). Zafar et al. (2010), Ahmed et al. (2011) and Ahmed et al. (2013) describe details for the seven site collections used in our study, the locations of which are shown in Fig. 1. Crossdating was performed under a microscope by matching patterns of narrow and wide rings between cores, and accounting for locally absent (i.e. "missing") and "false" rings for each core. The measurements of each ring were made to
$0.01 \mathrm{~mm}$ accuracy. We evaluated the accuracy of the crossdating for all sites using the statistical tree-ring quality control software COFECHA (Holmes 1983). After assuring that trees were accurately crossdated, ring-width measurements were standardized to remove and reduce non-climatic influences on tree growth by using the program ARSTAN (Cook 1985; Cook and Kairiukstis 1990). Prior to standardization, we employed the methodology of Cook and Peters (1997) where an adaptive power transform is performed, based on the local spread vs. level, in order to ensure homoscedasticity or stable variance through time. We used the 'Friedman Super Smoother' $(\alpha=6)$ for standardization (Buckley et al. 2007, 2010; Friedman 1984). The expressed population signal (EPS) statistic was used to interpret the quality of each individual chronology, using EPS $>0.85$ as the standard accepted threshold (Wigley et al. 1984) and this value along with all pertinent chronology statistics are included in the Supplementary Online Material (SOM).

\subsection{Climate data}

The Gilgit meteorological station $\left(35^{\circ} 55 \mathrm{~N}, 74^{\circ} 20 \mathrm{E}\right.$, $1454 \mathrm{~m}$ asl) is located in close proximity to most of the tree ring sites (Fig. 1). Although short (1955-2009), it is the longest such record in Northern Pakistan. Astore (35 $37^{\prime} \mathrm{N}$, $74^{\circ} 90 \mathrm{E}, 2167 \mathrm{~m}$ ) is approximately $115 \mathrm{~km}$ southeast of Gilgit and is farther away from our tree-ring locations. Astore's temperature data span 1960-2013 and agree well 
with the Gilgit station data. We therefore made a composite temperature dataset from both stations by preserving the statistical properties (mean, standard deviation) of the Gilgit station subsequent to confirming the homogeneity between the two datasets for each month for the common period (1960-2009). We then calculated the z-scores for both datasets and averaged them for the common period (1960-2009). The averaged z-scores were then converted to degrees Celsius by multiplying with the standard deviation and adding the mean of the Gilgit temperature. Finally, to account for the elevation difference between Gilgit (1454 m) and the mean elevation of our tree sites ( $3059 \mathrm{~m})$, we used the moist adiabatic lapse rate of $6.5^{\circ} \mathrm{C} / \mathrm{km}$ as a conservative estimate of the mean monthly temperature at the field sites to develop a 59-year record that spans form 1955-2013.

The mean annual temperature for the Gilgit-Astore composite is $5.5^{\circ} \mathrm{C}$, mean summer (JJA) temperature is $15.7^{\circ} \mathrm{C}$, and the mean temperature for the entire period from November through February remains below freezing. Box and whisker plots of mean monthly temperature are presented in Fig. 3, illustrating that summer temperature peaks in July and that January is the coldest month. We used the Gilgit-Astore temperature dataset for all ensuing analyses and for reconstruction of summer temperature from our seven-site tree ring matrix. For this purpose we used the Lamont-Doherty Earth Observatory Tree Ring Laboratory's freeware program PCReg (http://www.ldeo.columbia.edu/tree-ring-laboratory/ resources/software), which enables users to reduce data to principal components and to select varying parameters for screening predictors prior to regression.

For additional comparison with our tree ring sites and our Gilgit-Astore temperature reconstruction, we used gridded temperature data from the University of East Anglia's Climate Research Unit (UEA CRU), Ts3.21 $0.5^{\circ}$ lat $\mathrm{X} 0.5^{\circ}$ lon dataset (Harris et al. 2014), as well as the ASIA 2k temperature reconstruction of Cook et al. (2013a) and the PAGES 2k Consortium (2013). We also compared our reconstruction with the Monsoon Asia Drought Atlas Palmer Drought Severity Index (MADA-PDSI-Cook et al. 2010). For percentage cloudiness we used the diagnostic low-level cloud data from the NCEP/NCAR monthly dataset (Kalnay et al. 1996). All of these data were downloaded from the International Research Institute for Climate and Society and Lamont-Doherty Earth Observatory (IRI and LDEO) Climate Data Library and are available at http://iridl.ldeo.columbia.edu/.

\subsection{Reconstruction methodology}

To develop the reconstruction we first determined the climate season to which the trees were most sensitive by conducting diagnostic comparisons between all tree rings sites and Gilgit and Astore precipitation and temperature

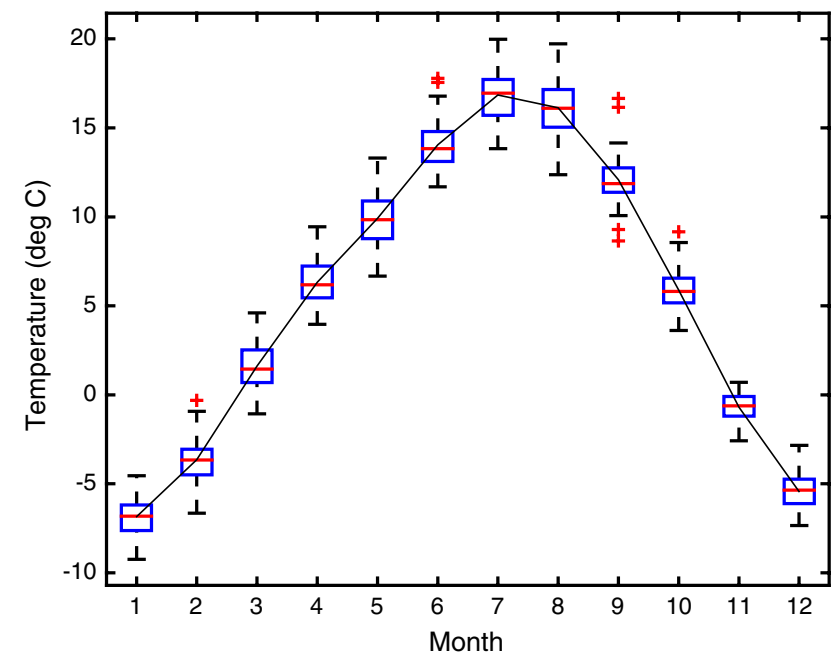

Fig. 3 Box plot of estimated mean monthly temperature at the mean elevation (3059 $\mathrm{m}$ asl) of the tree-ring sites based on the GilgitAstore station mean temperature (1955-2013). The temperature difference between tree-ring sites and stations was calculated by using a moist adiabatic lapse rate of $6.5^{\circ} \mathrm{C} / \mathrm{km}$. Red squares in the figure show outliers, and the black line connects the mean temperature for each month in sequence

(Fig. 4a, Fig. S1-S3). For this purpose we used a 24-month dendroclimatic window, where the 12 calendar months for the year of growth (year $t 0$ ) as well as the year prior to growth (year $t-1$ ) were analyzed via point-by-point regression. The prior year was used to account for the tendency of conifers to "carry over" the effects of prior year's growth (Fritts 1976).

To extract the common signal from the seven chronologies we conducted a principal component analysis (PCA-Cooley and Lohnes 1971) based on the common period of 1737-2005. We retained the first two Principal Components (PC1 and PC2) based upon their eigenvalues exceeding the selection criteria of one, and they explain 67.3 and $13.9 \%$ of the total variance, respectively. We then used the 'PC scores' to develop a regression model with the Gilgit-Astore temperature series. In order to maximize the timespan of our reconstruction we performed a similar procedure twice more, after dropping the Chera Picea (1394-2005) site, and Chaprot Pinus (1737-2008) site, and we then combined the three reconstructions to develop the final nested reconstruction that spans the period from 1523-2007. All of the Picea time series loaded positively onto PC1, while the lone Pinus site loaded onto PC2.

These analyses showed that summer temperature (i.e., the months of June, July and August or JJA) exhibited the most consistent correlation (negative) with our trees for current year and prior year. The strongest correlation for the six spruce sites is concentrated in prior year's temperature and the lone pine site correlates best with current 


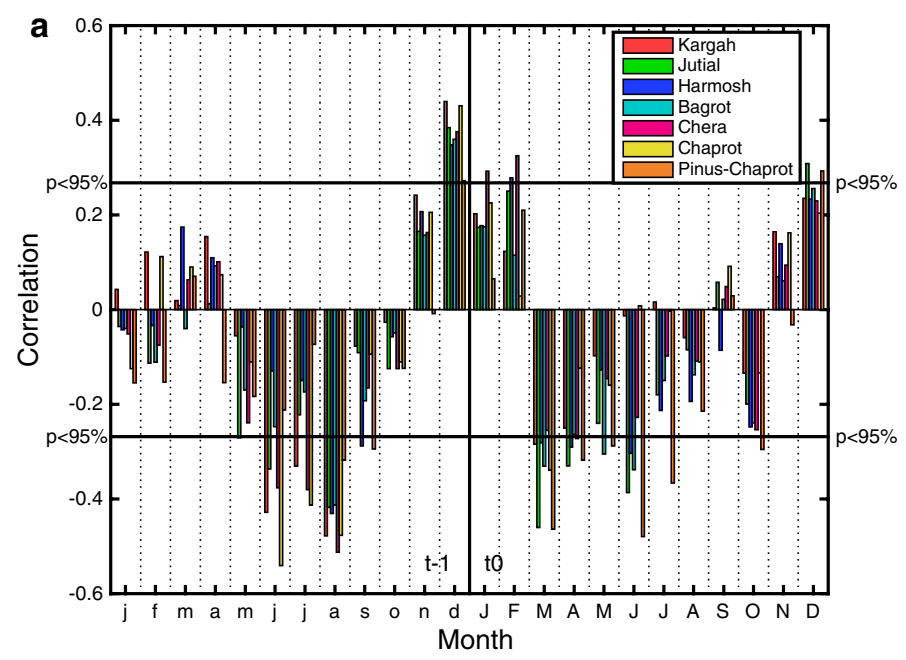

Fig. 4 Pearson's correlation between monthly Gilgit-Astore temperatures for a 24-month window from the prior year $(t-1)$ January to the current year $\left(\mathrm{t}_{0}\right)$ December and tree ring indices. The panel a on the left shows the correlation between temperature and residual tree-ring indices from each of the seven sites, while on the right $\mathbf{b}$ we show correlation between temperature and first two PC scores from

year (Fig. 4). Precipitation showed lower correlations than temperature, suggesting that temperature is the dominant limiting factor to tree-growth in this region (Fig. S1-S3). We note, however, that the inverse response to temperature may be interpreted as some form of moisture stress in our trees, so we tested for a relationship between precipitation and growth using both instrumental station records (Gilgit, Astore, Skardu), and gridded datasets (CRU) and still found the relationship to be weaker than that of temperature (not shown).

To verify the fidelity of our reconstruction we applied a split calibration and verification scheme using the GilgitAstore meteorological station data (Table 2). Two separate 30-year periods (1955-1985 and 1975-2004) were used, and we determined our reconstruction to be robust during both periods but particularly so when calibrated on the early half of the record. To determine robustness we utilized the Reduction of Error (RE), Coefficient of Efficiency (CE), and the Durbin-Watson statistics, which are commonly used for dendroclimatic reconstruction (Cook and Kairiukstis 1990). RE and CE measure the shared variance between actual and reconstructed temperature, while the Durbin-Watson statistic is used to detect autocorrelation between residuals between the actual and reconstructed temperatures (for more details see Cook and Kairiukstis 1990). Values for RE and CE are, by definition, equal for the calibration periods, but are not constrained to be so for independent verification where $\mathrm{CE}$ is notoriously difficult to pass (ibid.). Although there is no statistical significance test for CE per se, any values greater than zero

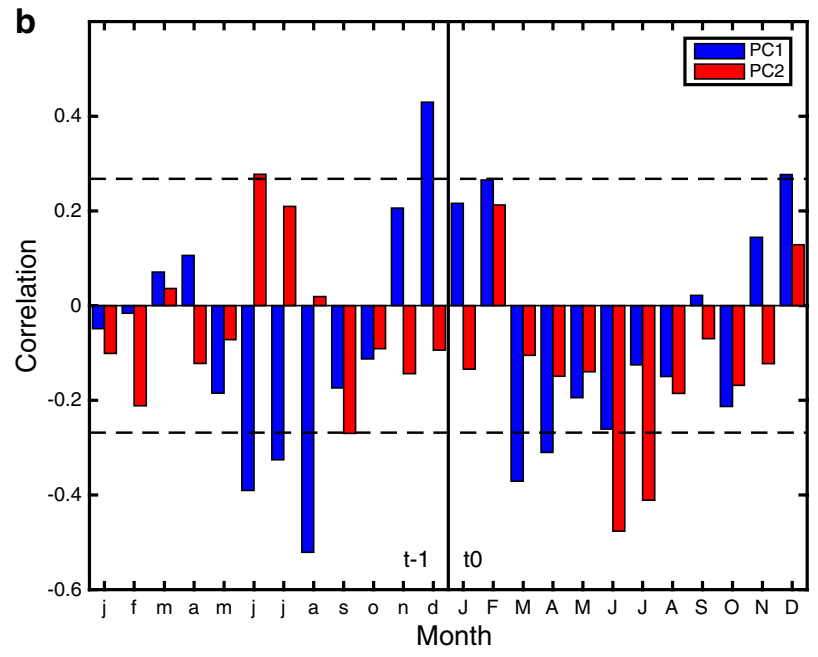

our chronology network (PC1 and PC2) for the timespan of 19552005 . The horizontal solid line at \pm 0.268 represents the $95 \%$ confidence interval for a two-sided Students' $t$ test. This study reconstructs June-August (JJA) temperature using PC1 and PC2, which show highest loading on the six spruce and lone pine sites respectively

during verification demonstrates model skill. In all cases (using undifferenced data in our verification) $\mathrm{CE}$ exceeds zero. The Durbin-Watson statistic in all instances is greater than one, indicating low autocorrelation between residuals, and underscoring the lack of a persistent error bias in our regression. These results establish that our regression model has skill, presents no consistent bias, and therefore the reconstruction is robust in spite of the relatively short length of record. The final reconstruction was developed using the entire period (1955-2009), and explains $41.00 \%$ of the total variance of nested station JJA temperature (Fig. 5, upper left panel), resulting in a 485-year (15232007 C.E.) reconstruction of Gilgit-Astore summer temperature (Fig. 5, lower left panel). Each of the individual tree ring indices and sample size are shown in the upper right panel of Fig. 5.

\section{Results and discussion}

Here we present our reconstruction of Karakorum summer (JJA) temperature for the period 1523-2007 (Fig. 5, lower left panel). To check the validity of our reconstruction over a larger spatial domain we correlated our temperature reconstruction to the CRU gridded temperatures and found that our reconstruction correlates positively ( $p<0.1$, twosided $t$ test, 1901-2004) with temperature from a broad spatial area that covers the Kashmir regions of Pakistan and India, northern Khyber Pakhtunkhwa (formerly Northwest Frontier Provinces), Tajikistan, Kyrgyzstan, northeastern 

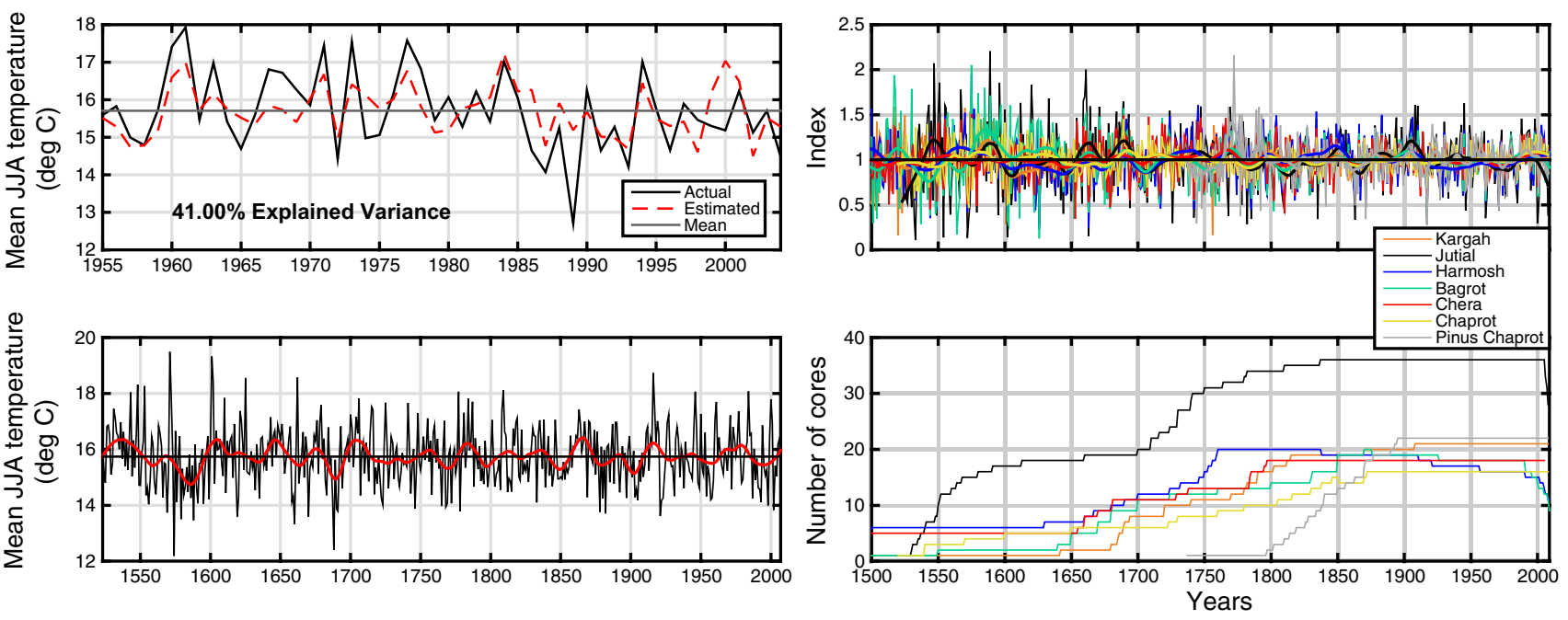

Fig. 5 The upper left panel shows a comparison between reconstructed June-August (JJA) temperatures (red dashed line) and Gilgit-Astore temperature (solid black line; $\mathrm{r}=0.6403, p<0.001$, 1955-2004, two-sided $t$ test); the lower left panel plots the JJA mean temperature reconstruction for full period 1523-2007 as degrees Cel-

Afghanistan, and western Xinjiang, China (Fig. 6, left). The striking inverse pattern between temperatures in the Karakorum with those in peninsular India is very similar to the temperature pattern across Asia as a result of the summer circum-global wavetrain (Ding and Wang 2005). We also compared our reconstruction with the (Cook et al. 2013a) Central and High Asia hemispheric-scale temperature reconstruction and observed an out-of-phase relationship in low frequency variability (20-40 years) between the two (Fig. 2, bottom panel). For example, the pronounced 1800s cold period in High Asia related to the Little Ice Age, is absent in our reconstruction. We note that our seven Karakorum records were also used in the Cook et al. (2013a) reconstruction, but their High Asia record is heavily biased towards tree rings from the Himalayas and Central Asia (a total of 585 tree ring records were used).

Our reconstruction correlates inversely with the (Cook et al. 2010) tree-ring based Palmer Drought Severity Index (PDSI) reconstruction, while the same opposite sign pattern between the Himalaya and peninsular India is also clearly depicted (Fig. 6, right). Since PDSI is a proxy for soil moisture conditions and is a metric used to measure drought (Palmer 1965), positive values are reflective of increasing soil moisture while negative values reflect dry conditions. Soil moisture increases with increased precipitation and decreases with increasing temperature, though other factors like wind coefficients and saturation vapor pressure deficits are also important (Allen et al. 1998). The MADA is a reconstruction of June-August (JJA) PDSI for Monsoon sius; the upper right panel is a stack of each of the seven residual chronology indices; the lower right panel shows the sample size (n) for each site (colored lines) and for the entire nested reconstruction (black line)

Asia from 1300 to 2005 (Cook et al. 2010) and thus is directly comparable to our summer temperature reconstruction. It is therefore reassuring that our Gilgit-Astore summer temperature reconstruction is inversely related to PDSI over the region around Gilgit-Astore (Fig. 6, right), such that an increase in summer temperature leads to greater soil moisture deficit, reduced photosynthetic potential and a corresponding decrease in radial growth (sensu Fritts 1976).

As mentioned earlier only one-third of the annual precipitation in the region falls in the summer monsoon season, whereas the majority is from westerly cyclonic storm systems (Benn and Owen 1998; Bookhagen and Burbank 2010; Dimri 2006; Gardelle et al. 2012; Hewitt et al. 1988; Hewitt 2005; Kapnick et al. 2014). During spring and summer the trees have access to additional moisture in the form of snowmelt. The trees in four of the seven sites are growing on north facing slopes, and one each on northwest, east, and east-south facing slopes (Table 1). This serves to insulate them from the higher evaporative stress common to south and west facing slopes. In this particular region, moist-temperate trees like spruce (Picea), and pines (Pinus) tend to be found on moist north facing slopes, and only junipers (Juniperus) can grow on south facing slopes (Esper 2000). Given the lack of a strict seasonality in precipitation, access to snowmelt, and slope aspect, the absence of a significant relationship between tree-growth and precipitation is not surprising. Consequently, given the robust relationship between summer temperature and growth, we targeted JJA mean temperature for reconstruction. 


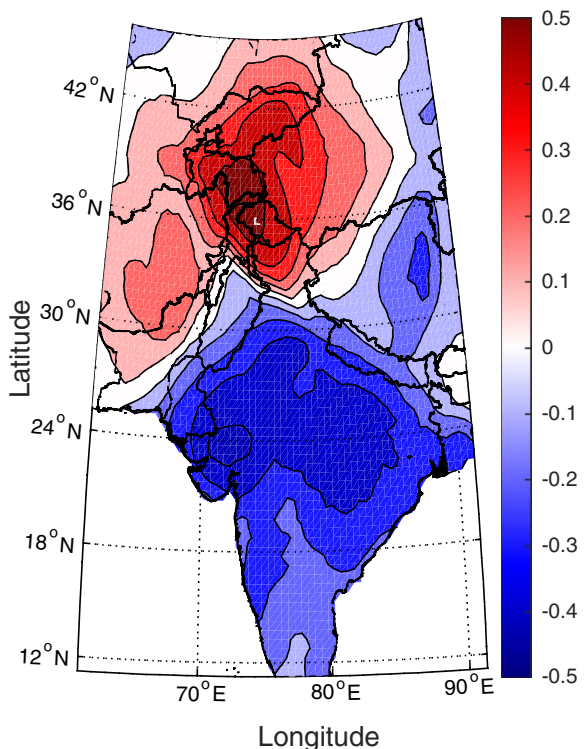

Fig. 6 Left spatial correlation field between the Gilgit-Astore JJA temperature reconstruction and gridded CRU Ts 3.21 temperature between 1901-2004 (only $p<0.1$ shown); Right correlation between Gilgit JJA temperature reconstruction and Cook et al. 2010 JJA PDSI

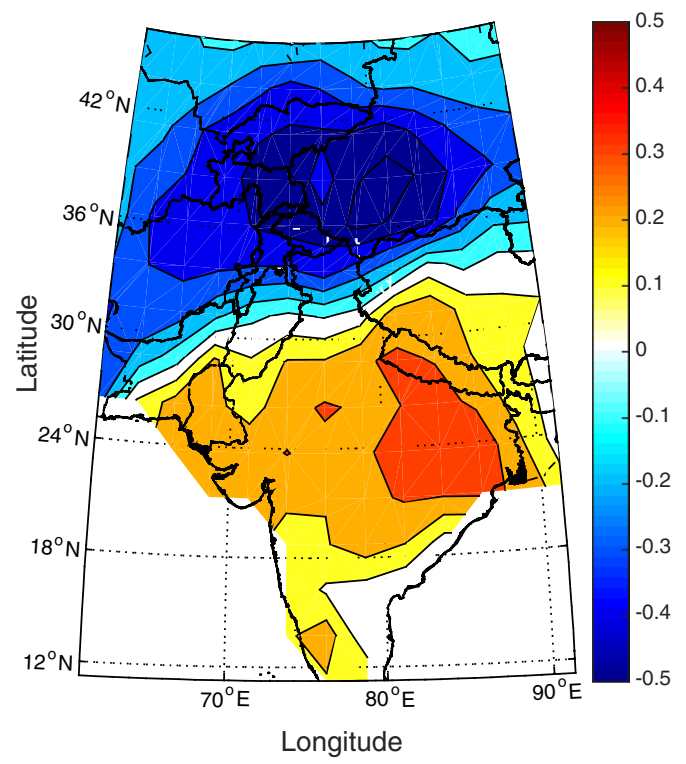

(1737-2004). The location of boundary lines are as per shape files downloaded from http://www.diva-gis.org/gdata and these boundary designations may differ from the official maps of the Governments of Pakistan, India, and Tajikistan

Table 1 Details of site locations and tree-ring indices

\begin{tabular}{|c|c|c|c|c|c|c|c|c|c|c|c|}
\hline \multirow[t]{2}{*}{ Sr. no } & \multirow[t]{2}{*}{ Species } & \multirow[t]{2}{*}{ Site } & \multicolumn{2}{|l|}{ Year } & \multirow[t]{2}{*}{ No. of cores } & \multirow[t]{2}{*}{$\mathrm{AR}(1)$} & \multirow[t]{2}{*}{ Lat } & \multirow[t]{2}{*}{ Lon } & \multirow[t]{2}{*}{ Elev (m) } & \multirow[t]{2}{*}{ Slope } & \multirow[t]{2}{*}{ Aspect } \\
\hline & & & First & Last & & & & & & & \\
\hline \multicolumn{12}{|c|}{ Gilgit valley sites } \\
\hline 1 & Picea smithiana & Kargah & 1475 & 2008 & 21 & 0.4735 & $35^{\circ} 53$ & $74^{\circ} 11$ & 2989 & $34^{\circ}$ & NW \\
\hline 2 & P. smithiana & Jutial & 1523 & 2008 & 36 & 0.4281 & $35^{\circ} 50$ & $74^{\circ} 20$ & 3250 & $40^{\circ}$ & $\mathrm{N}$ \\
\hline 3 & P. smithiana & Harmosh & 1467 & 2009 & 20 & 0.4678 & $35^{\circ} 53$ & $74^{\circ} 53$ & 3296 & $53^{\circ}$ & $\mathrm{E} / \mathrm{S}$ \\
\hline 4 & P. smithiana & Bagrot & 1480 & 2009 & 20 & 0.5150 & $36^{\circ} 01$ & $74^{\circ} 36$ & 3130 & $45^{\circ}$ & $\mathrm{E}$ \\
\hline 5 & P. smithiana & Chera & 1394 & 2005 & 18 & 0.5046 & $36^{\circ} 90$ & $74^{\circ} 11$ & 2900 & $36^{\circ}$ & $\mathrm{N}$ \\
\hline \multicolumn{12}{|c|}{ Hunza valley sites } \\
\hline 1 & P. smithiana & Chaprot & 1520 & 2008 & 16 & 0.7249 & $36^{\circ} 14$ & $74^{\circ} 16$ & 3000 & $35^{\circ}$ & $\mathrm{N}$ \\
\hline 2 & Pinus gerardiana & Chaprot & 1737 & 2008 & 22 & 0.5291 & $36^{\circ} 14$ & $74^{\circ} 16$ & 2850 & $26^{\circ}$ & $\mathrm{N}$ \\
\hline
\end{tabular}

The column AR(1) shows the first order autocorrelation of the standardized tree ring indices; Lat latitude, Lon longitude, Elev elevation

Table 2 Calibration and verification statistics of the Gilgit JJA temperature reconstruction

\begin{tabular}{|c|c|c|c|c|c|}
\hline & Calibration & Verification & Calibration & Verification & Reconstruction \\
\hline & $1955-1985$ & 1987-2004 & 1975-2004 & $1955-1973$ & 1955-2004 \\
\hline Durbin-Watson & 1.885 & & 1.7866 & & 1.6969 \\
\hline Variance explained & $54.04 \%$ & & $30.91 \%$ & & $41.00 \%$ \\
\hline $\mathrm{RE}$ & 0.593 & 0.255 & 0.350 & 0.511 & \\
\hline $\mathrm{CE}$ & 0.593 & 0.255 & 0.350 & 0.511 & \\
\hline PR & 0.804 & 0.530 & 0.601 & 0.790 & 0.6403 \\
\hline
\end{tabular}

The RE and CE measure the shared variance between the actual and reconstructed temperatures, and non-negative values indicate that the regression model has skill (Cook and Kairiukstis 1990)

$R E$ reduction of error, $C E$ coefficient of efficiency, $P R$ Pearson's correlation coefficient 
As mentioned above the dominant mode of common variability between six of the seven tree ring indices correlated most to prior year summer JJA temperatures. It is possible that this lagged, inverse response is due to the relatively short growing season. At high elevations conifer needles typically reach peak photosynthetic potential only in the next growing season, and thus climate of the previous year has a greater influence on current-year growth than it does on current year climate (Fritts 1976). We did not observe high sensitivity to precipitation, possibly due to the lack of seasonality of precipitation in this region, which is influenced both by summer monsoon moisture and winter westerly cyclonic systems causing precipitation to not be limiting to tree growth (Fig. S3). It is also possible that the poor quality and relative dearth of instrumented precipitation limits our ability to elucidate a clear response. However, we feel that the location of all of our tree sites at the upper elevational limits of their ecological amplitude, combined with their locations on slopes other than southerly, all point to the validity of our interpretation that temperature is the dominant limiting factor for all of our sites (Tables 2 and 3).

Hewitt (2005) proposed that an increase in summertime cloudiness from monsoonal moisture was one of the factors responsible for the cooling in the Karakorum, as clouds decrease incident solar insolation and hence temperature. We too find that there is a significant inverse relationship ( $\mathrm{r}=-0.60, p<0.01$, two-sided $t$ test, 1955-2013) between percentage low-level cloudiness and summer temperature, and an increasing trend in cloudiness since the 1960s that tracks the dramatic rise in the Cook et al. (2013a) High Asia temperature reconstruction (see Fig. 7, left). Interestingly, while temperatures in the High Asia reconstruction increase dramatically after the 1960 s, our reconstruction shows a slight decrease.

Phillips et al. (2000) developed an ice core chronology from the Nanga Parbat glacier, approximately $80 \mathrm{~km}$ south of Gilgit (Fig. 1). Their study shows that Karakorum ice volumes expanded during warm and wet climatic optima, when monsoon activity was enhanced, and decreased during historical periods of glacial maxima when monsoons were weak. This behavior is typical of high-elevation arid glaciers that are precipitation limited (Rupper and Roe 2008) and is reflective of the relationship between Eurasian snow cover and the strength of the Indian Monsoon as noted by Chang et al. (2001) and Dash et al. (2005). In other words, increased Eurasian snow cover is correlated with a weaker land-sea thermal contrast, and hence the inland extent of monsoonal moisture in this region is reduced. The Karakorum lies outside of the influence of all but the strongest of monsoonal incursions, at the northernmost reach of a typical monsoon. Hence even a slight reduction in monsoon vigor may reduce summer
Table 3 The five coldest and warmest single year (top) and 10-year periods (bottom) as determined from our tree-ring reconstruction of Karakorum temperature

\begin{tabular}{|c|c|c|c|c|}
\hline & Year & Temperature $\left({ }^{\circ} \mathrm{C}\right)$ & Year & Temperature $\left({ }^{\circ} \mathrm{C}\right)$ \\
\hline & \multicolumn{2}{|c|}{ Coldest 1 year } & \multicolumn{2}{|c|}{ Warmest 1 year } \\
\hline 1 & 1574 & 12.19 & 1571 & 19.48 \\
\hline 2 & 1688 & 12.40 & 1601 & 19.32 \\
\hline 3 & 1660 & 13.32 & 1916 & 18.72 \\
\hline 4 & 1588 & 13.47 & 1662 & 18.56 \\
\hline \multirow[t]{2}{*}{5} & 1579 & 13.51 & 1625 & 18.56 \\
\hline & \multicolumn{2}{|c|}{ Coldest 10 year } & \multicolumn{2}{|c|}{ Warmest 10 year } \\
\hline 1 & $1683-1692$ & 14.70 & $1911-1920$ & 16.75 \\
\hline 2 & $1584-1593$ & 14.77 & $1599-1608$ & 16.59 \\
\hline 3 & 1950-1949 & 15.01 & $1698-1707$ & 16.56 \\
\hline 4 & $1552-1563$ & 15.01 & $1860-1869$ & 16.49 \\
\hline 5 & 1901-1910 & 15.03 & $1642-1651$ & 16.46 \\
\hline
\end{tabular}

precipitation and cloudiness, serving to increase temperature in valleys like Gilgit and Hunza.

\section{Conclusions}

In this paper we present a reconstruction of summer temperature that reveals that the northern Karakorum has been continuously out of phase with hemispheric-scale temperature for at least the past five centuries, as compared to the 'High Asia' temperature reconstruction of Cook et al. (2013a), and the PAGES 2k Consortium (2013) (Fig. 2). We believe, therefore, that our temperature reconstruction validates the localized cooling trend in the Karakorum and Gilgit valleys since the 1960s that is swamped by the overall warming signal at the hemispheric scale. Fowler and Archer (2006) and Shekhar et al. (2010) analyzed Karakorum instrumental data, including Gilgit, and confirmed that summertime temperature has cooled since the 1960s while the hemisphere at large warmed.

All seven of our tree ring indices correlate inversely with both temperature and PDSI, and do not show significant relationships with precipitation, suggesting that temperature and not precipitation is the primary limiting factor for tree growth in this region. In essence, due to annual snowpack and proximity to river drainage, trees in the Gilgit and Hunza valleys are not easily stressed by low soil moisture, and photosynthesis is most likely to be controlled by the range in temperature. Our reconstruction shows that summer temperatures in the Karakorum have decreased, and one of the factors contributing to this decrease is increased summer cloudiness (Fowler and Archer 2006; Hewitt 2005). We believe that this temperature decrease, coupled with increased cloudiness, has contributed to the 


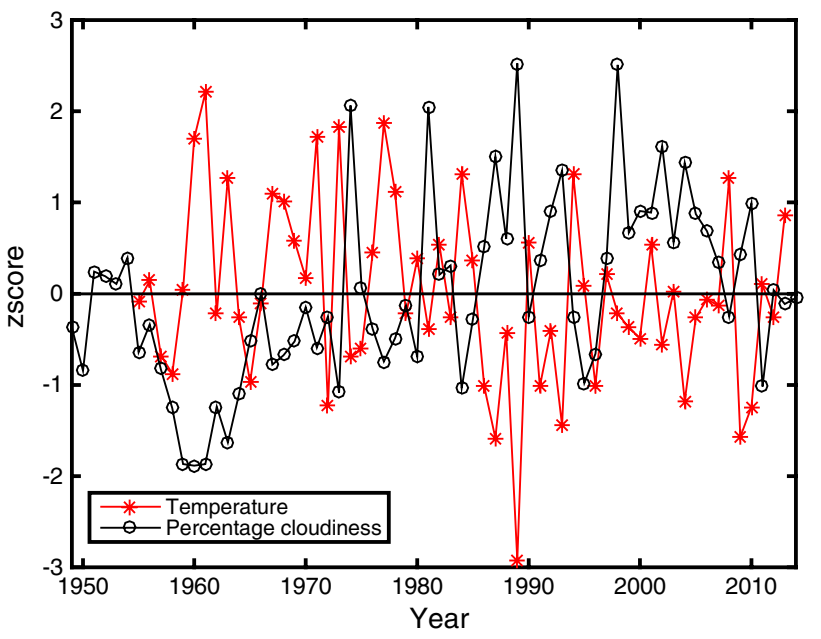

Fig. 7 The plot on the left shows the z-scores of the Gilgit-Astore JJA instrumental temperature (red line) against percentage JJA lowlevel cloudiness from NCEP-NCAR (Kalnay et al. 1996) (black

'Karakorum Anomaly' of glacial stability and in some cases expansion during a period of otherwise widespread glacial retreat. The other contributing factor to the anomaly, as mentioned in other previous studies is the recent increase in winter snowfall (Farhan et al. 2015; Kapnick et al. 2014; Ridley et al. 2013; Tahir et al. 2011). In a recent paper Kumar et al. (2015) used a regional climate model (RCM), with dynamically evolving glaciers to simulate the annual glacial mass balance for the period 1989-2008 over the Himalayas and the Karakorum (see Fig. 3 of Kumar et al. 2015). Their simulations also indicate an increasing glacial mass balance over some regions of the Karakorum. However, they too show that the increasing mass balance is the exception and not the norm, and is limited to a small region of the Karakorum where all of our sites are located. Importantly, we demonstrate with our reconstruction that this out-of-phase temperature relationship between the Karakorum and the hemisphere at large has persisted for at least the past five centuries.

Acknowledgments We express gratitude towards the people of Gilgit and Hunza valleys who assisted with the fieldwork for this project. We thank Dr. Joerg Schaefer (Lamont-Doherty Earth Observatory) for insightful comments that improved the manuscript. We also thank Dr. Paolo Cherubini (Swiss Federal Research Institute) for comments on an earlier version of this manuscript. We are grateful to the Pakistan Meteorological Department for providing climate data. We also express thanks to Dr. Andrew Bell (New York University), Dr. Sonali McDermid (New York University), and Dr. Muhammad Ashfaq for sharing climate data and thank two anonymous reviewers for their comments and suggestions that substantially improved this manuscript. The authors acknowledge funding 20 - 1806/R AND D/10. 5149.IT from the Higher Education Commission, Government of Pakistan. Funding for B.M. Buckley and M.P. Rao came from the support of the US National Science Foundation (AGS 13-03976 and AGS 12-03818). Lamont Contribution No. 7904.

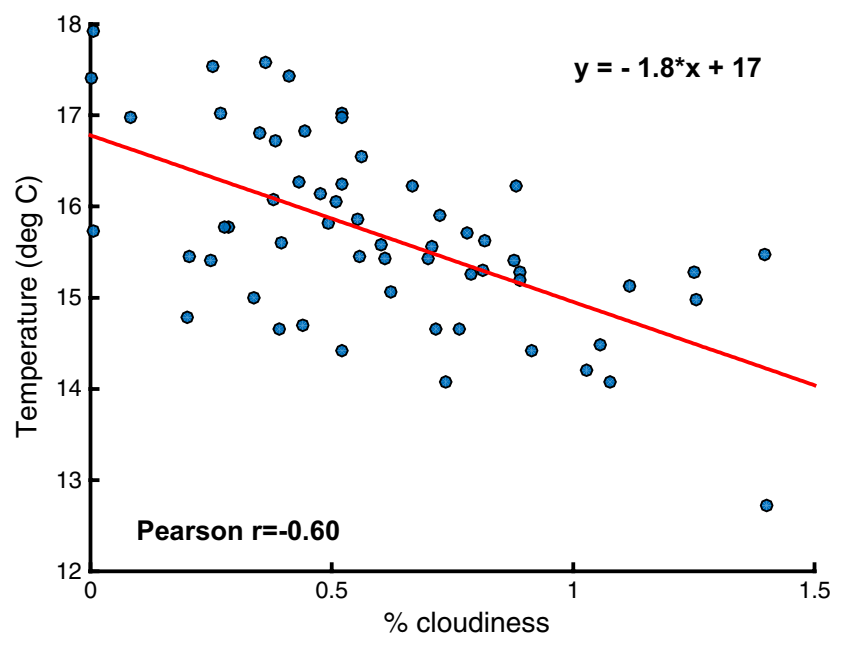

line). Note the increasing trend in percentage cloudiness from 1960 to 2005. The scatter plot on the right shows the inverse relationship between the two $(\mathrm{r}=-0.6, p<0.001$, two-sided $t$ test, 1955-2013)

\section{References}

Ahmed M, Palmer J, Khan N, Wahab M, Fenwick P, Esper J, Cook E (2011) The dendroclimatic potential of conifers from northern Pakistan. Dendrochronologia 29:77-88

Ahmed M, Zafar MU, Hussain A, Akbar M, Wahab M, Khan N (2013) Dendroclimatic and dendrohydrological response of two tree species from Gilgit valleys. Pak J Botany 45:987-992

Allen RG, Pereira LS, Raes D, Smith M (1998) Crop evapotranspiration-guidelines for computing crop water requirements-FAO irrigation and drainage paper 56. FAO, Rome

Benn D, Owen L (1998) The role of the Indian summer monsoon and the mid-latitude westerlies in Himalayan glaciation: review and speculative discussion. J Geol Soc 155:353-363

Bolch T, Kulkarni A, Kääb A, Huggel C, Paul F, Cogley J, Frey H, Kargel JS, Fujita K, Scheel M (2012) The state and fate of Himalayan glaciers. Science 336:310-314

Bookhagen B, Burbank DW (2010) Toward a complete Himalayan hydrological budget: spatiotemporal distribution of snowmelt and rainfall and their impact on river discharge. J Geophys Res Earth Surf (2003-2012) 115(F3). doi:10.1029/2009JF001426

Buckley BM, Palakit K, Duangsathaporn K, Sanguantham P, Prasomsin P (2007) Decadal scale droughts over northwestern Thailand over the past 448 years: links to the tropical Pacific and Indian Ocean sectors. Clim Dyn 29:63-71

Buckley BM, Anchukaitis KJ, Penny D, Fletcher R, Cook ER, Sano M, Wichienkeeo A, Minh TT, Hong TM (2010) Climate as a contributing factor in the demise of Angkor, Cambodia. Proc Natl Acad Sci 107:6748-6752

Chang C, Harr P, Ju J (2001) Possible roles of Atlantic circulations on the weakening Indian monsoon rainfall-ENSO relationship. J Clim 14:2376-2380

Cook ER (1985) A time series analysis approach to tree ring standardization. Doctoral dissertation, University of Arizona, Chicago

Cook ER, Kairiukstis LA (1990) Methods of dendrochronology: applications in the environmental sciences. Springer, Berlin

Cook ER, Peters K (1997) Calculating unbiased tree-ring indices for the study of climatic and environmental change. The Holocene 7:361-370 
Cook ER, Krusic PJ, Jones PD (2003) Dendroclimatic signals in long tree-ring chronologies from the Himalayas of Nepal. Int J Climatol 23:707-732

Cook ER, Anchukaitis KJ, Buckley BM, D’Arrigo RD, Jacoby GC, Wright WE (2010) Asian monsoon failure and megadrought during the last millennium. Science 328:486-489

Cook ER, Krusic PJ, Anchukaitis KJ, Buckley BM, Nakatsuka T, Sano M (2013a) Tree-ring reconstructed summer temperature anomalies for temperate East Asia since 800 CE. Clim Dyn 41:2957-2972

Cook ER, Palmer JG, Ahmed M, Woodhouse CA, Fenwick P, Zafar MU, Wahab M, Khan N (2013b) Five centuries of Upper Indus River flow from tree rings. J Hydrol 486:365-375

Cooley WW, Lohnes PR (1971) Multivariate data analysis. Wiley, New York

D'Arrigo R, Wilson R, Jacoby G (2006) On the long-term context for late twentieth century warming. J Geophys Res Atmos (19842012) 111(D3). doi:10.1029/2005JD006352

Dash S, Singh G, Shekhar M, Vernekar A (2005) Response of the Indian summer monsoon circulation and rainfall to seasonal snow depth anomaly over Eurasia. Clim Dyn 24:1-10

Davi N, D'Arrigo R, Jacoby G, Cook ER, Anchukaitis K, Nachin B, Rao MP, Leland C (2015) A long-term context (931-2005 C.E.) for rapid warming over Central Asia. Quat Sci Rev. doi:10.1016/j.quascirev.2015.05.020

Dey B, Kumar O (1983) Himalayan winter snow cover area and summer monsoon rainfall over India. J Geophys Res Oceans (19782012) 89:5471-5474

Dimri A (2006) Surface and upper air fields during extreme winter precipitation over the western Himalayas. Pure Appl Geophys 163:1679-1698

Ding Q, Wang B (2005) Circumglobal teleconnection in the northern hemisphere summer*. J Clim 18:3483-3505

Douville H, Royer J-F (1996) Sensitivity of the Asian summer monsoon to an anomalous Eurasian snow cover within the MeteoFrance GCM. Clim Dyn 12:449-466

Esper J (2000) Long-term tree-ring variations in Juniperus at the upper timber-line in the Karakorum (Pakistan). The Holocene 10:253-260

Esper J, Schweingruber FH, Winiger M (2002) 1300 years of climatic history for Western Central Asia inferred from tree-rings. The Holocene 12:267-277

Farhan S, Zhang Y, Ma Y, Guo Y, Ma N (2015) Hydrological regimes under the conjunction of westerly and monsoon climates: a case investigation in the Astore Basin, Northwestern Himalaya. Clim Dyn 44:3015-3032. doi:10.1007/s00382-014-2409-9

Fowler H, Archer D (2006) Conflicting signals of climatic change in the Upper Indus Basin. J Clim 19:4276-4293

Friedman JH (1984) A variable span smoother (No. LCS-TR-5). Stanford Univ CA lab for computational statistics

Fritts H (1976) Tree rings and climate. Elsevier, New York

Gardelle J, Berthier E, Arnaud Y (2012) Slight mass gain of Karakoram glaciers in the early twenty-first century. Nat Geosci 5:322-325

Harris I, Jones P, Osborn T, Lister D (2014) Updated high-resolution grids of monthly climatic observations-the CRU TS3. 10 Dataset. Int J Climatol 34:623-642

Hewitt K (2005) The Karakoram anomaly? Glacier expansion and the 'elevation effect', Karakoram Himalaya. Mt Res Dev 25:332-340

Hewitt K, Wake C, Young G, David C (1988) Hydrological investigations at Biafo Glacier, Karakorum Range, Himalaya; an important source of water for the Indus River. Ann Glaciol 13:103-108
Hewitt K, Gosse J, Clague JJ (2011) Rock avalanches and the pace of late quaternary development of river valleys in the Karakoram Himalaya. Geol Soc Am Bull 123:1836-1850

Holmes RL (1983) Computer-assisted quality control in tree-ring dating and measurement. Tree-ring Bull 43:69-78

IPCC (2014) Climate change 2013: the physical science basis: working group I contribution to the fifth assessment report of the Intergovernmental Panel on Climate Change. Cambridge University Press, Cambridge

Kalnay E, Kanamitsu M, Kistler R, Collins W, Deaven D, Gandin L, Iredell M, Saha S, White G, Woollen J (1996) The NCEP/NCAR 40-year reanalysis project. Bull Am Meteorol Soc 77:437-471

Kapnick SB, Delworth TL, Ashfaq M, Malyshev S, Milly P (2014) Snowfall less sensitive to warming in Karakoram than in Himalayas due to a unique seasonal cycle. Nat Geosci 7:834-840

Krusic, PJ, Cook ER, Dukpa D, Putnam AE, Rupper S, Schaefer J (2015) Six hundred thirty-eight years of summer temperature variability over the Bhutanese Himalaya. Geophys Res Lett 42:2988-2994. doi:10.1002/2015GL063566

Kumar P, Kotlarski S, Moseley C, Sieck K, Frey H, Stoffel M, Jacob D (2015) Response of Karakoram-Himalayan glaciers to climate variability and climatic change: a regional climate model assessment. Geophys Res Lett 42:1818-1825

Li C, Yanai M (1996) The onset and interannual variability of the Asian summer monsoon in relation to land-sea thermal contrast. J Clim 9:358-375

Minora U, Bocchiola D, D’Agata C, Maragno D, Mayer C, Lambrecht A, Mosconi B, Vuillermoz E, Senese A, Compostella C (2013) 2001-2010 glacier changes in the Central Karakoram National Park: a contribution to evaluate the magnitude and rate of the "Karakoram anomaly". Cryosphere Discuss 7:2891-2941

PAGES 2k Consortium (2013) Continental-scale temperature variability during the last two millennia. Nat Geosci 6:339-346

Palazzi E, von Hardenberg J, Terzago S, Provenzale A (2015) Precipitation in the Karakoram-Himalaya: a CMIP5 view. Clim Dyn 45:21-45. doi:10.1007/s00382-014-2341-z

Palmer WC (1965) Meteorological drought. US Department of Commerce, Weather Bureau, Washington, DC

Phillips WM, Sloan VF, Shroder JF, Sharma P, Clarke ML, Rendell HM (2000) Asynchronous glaciation at Nanga Parbat, northwestern Himalaya Mountains, Pakistan. Geology 28:431-434

Ridley J, Wiltshire A, Mathison C (2013) More frequent occurrence of westerly disturbances in Karakoram up to 2100. Sci Total Environ 468:S31-S35

Rupper S, Roe G (2008) Glacier changes and regional climate: a mass and Energy balance approach*. J Clim 21:5384-5401

Shekhar M, Chand H, Kumar S, Srinivasan K, Ganju A (2010) Climate-change studies in the western Himalaya. Ann Glaciol 51:105-112

Stokes MA, SmileyTL (1968) An introduction to tree-ring dating. University of Chicago Press, Chicago

Tahir AA, Chevallier P, Arnaud Y, Neppel L, Ahmad B (2011) Modeling snowmelt-runoff under climate scenarios in the Hunza River basin, Karakoram Range, Northern Pakistan. J Hydrol 409:104-117

Wigley TM, Briffa KR, Jones PD (1984) On the average value of correlated time series, with applications in dendroclimatology and hydrometeorology. J Clim Appl Meteorol 23:201-213

Zafar MU, Ahmed M, Farooq MA, Akbar M, Hussain A (2010) Standardized tree ring chronologies of Picea smithiana from two new sites of Northern area Pakistan. World Appl Sci J 11:1531-1536 